\title{
Silica-dendrimer nanohybrid materials as adsorbents for heavy metal ions in aqueous solutions
}

\author{
Mateusz Pawlaczyk ${ }^{1}$, Maria Guć1, Grzegorz Schroeder ${ }^{1}$ \\ Adam Mickiewicz University in Poznan, Faculty of Chemistry \\ Umultowska 89b, 61-614 Poznan, Poland \\ mateusz.pawlaczyk@amu.edu.pl; maria.guc@amu.edu.pl; schroede@amu.edu.pl
}

\begin{abstract}
Global industrialization generates still growing water contamination, connected with appearance of primarily heavy metal ions and toxic organic compounds. Therefore, designing and synthesis of novel adsorbents is highly explored part of materials science. In the recent years, a broad range of inorganic-organic hybrid materials drew attention as potential sorbents designated for heavy metal removal, according to their versatile usefulness and flexible modulation of chelating properties by the choice of functionalizing agent. The main objective of following study was to synthesize a series of poly(amidoamine) dendrimers with tris(2-aminoethyl)amine as amine core, which constituted the grafting nanoagents for silica surface, leading to novel hybrid materials designated as adsorbents toward heavy metal ions: $\mathrm{Cu}^{2+}, \mathrm{Ni}^{2+}$ and $\mathrm{Co}^{2+}$. The synthetic approach involved synthesis of four dendrimers containing structurally diverse amines: ethylenediamine, triethylenetetramine, tris(2-aminoethyl)amine and 4,7,10-trioxa-1,13tridecanediamine and their subsequent grafting onto isocyanate-functionalized silica particles. Synthesized dendrimers were characterized with NMR and ESI-MS analysis, while successful grafting of dendrimers onto silica surface was confirmed by IR spectroscopy. Obtained hybrid materials, containing nanosized dendrimers on their surface, were studied for adsorptive properties toward heavy metal ions, including determination of adsorption isotherms, as well as performing kinetic and thermodynamic studies, using spectrophotometric assays. On the basis of adsorption experiments, various coefficients such as maximal adsorption capacities, standard Gibbs free energies and adsorption rate constants were established, which values considerably varied for each material. According to obtained data, appearance of structurally diverse amines in grafting agents significantly influences the chelating properties of silica-based hybrid materials. Satisfactory results of conducted studies might contribute to designing of novel adsorbents, finding utilization in removal or pre-concentration of analytes, as well as in gradual sorption of bioactive molecules.
\end{abstract}

Keywords: Poly(amidoamine) dendrimers, Silica particles, Hybrid materials, Grafting nanoagent, Heavy metal adsorption, Langmuir isotherm.

\section{Introduction}

Water contamination is one of the major problem connected with incremental expansion of industry. Globally, heavy metal ions and toxic organic compounds (such as organic dyes, aromatic compounds or pesticides) represent the biggest threat towards water and soil [1-4]. In order to prevent their negative impact on the biological viability of animals and plants, the field of designing and synthesis of novel adsorbents is highly explored. Recently, considerable attention has been paid to the group of hybrid materials, which states the conjugation of inorganic or organic platform and organic functionalizing agent. The main principle of hybrid materials' designing involves choice of nontoxic, easy tuneable platform (e.g. silica, magnetic $\mathrm{Fe}_{3} \mathrm{O}_{4}$ nanoparticles, biocompatible polymers) and non-hazardous, specifically binding functionalizing agent (e.g. amino acids, surfactants, peptide or saccharide domains, chelating agents, dendrimers), which therefore contributes to high efficiency toward particular pollutants, easy separation and recoverability of sorbents [5-9].

The aim of our work was to synthesize and study adsorptive properties of silica-gel particles grafted with various poly(amidoamine) dendrimers towards heavy metal ions. The choice of exact dendrimers' kind was dictated by their postulated chelating properties [10] and nanosize, while utilization of various amino growth-components was applied in order to establish their influence on overall material's adsorptive capability. We proposed syntheses of nanoscaled dendrimers and their subsequent utilization as grafting nanoagents towards silica surface. The main objective was to utilize nanosized, chelating dendrimers, what stimulates adsorptive properties of final hybrid materials. Obtained adsorbents were investigated for adsorptive ability toward copper(II), cobalt(II) and nickel(II) ions, using spectrophotometric assays. Adsorption experiments involved producing of adsorption isotherms, and performing thermodynamic and kinetic studies. 


\section{Experimental}

\subsection{Synthesis of dendrimers}

Synthesis of poly(amidoamine) dendrimers were performed using general procedure describe in the literature [11]. Three-necked flask was equipped with solution methyl acrylate $(70.52 \mathrm{~g} ; 0.820 \mathrm{~mol})$ in $50 \mathrm{~mL}$ of methanol, maintaining anhydrous atmosphere. To a stirred solution, cooled in ice-water bath to temperature $0^{\circ} \mathrm{C}$, tris $(2$-aminoethyl)amine solution $(10 \mathrm{~g} ; 0.068 \mathrm{~mol})$ in methanol $(50 \mathrm{~mL})$ was added dropwise within 3 hours, not to allow temperature rise. Then, cooling bath was removed and mixture was stirred at room temperature for 7 days. After that time, excess of solvent and methyl acrylate was removed under reduced pressure, obtaining ester intermediate $\mathbf{1}$ - a precursor of desired dendrimer. To synthesize each dendrimer, general procedure was used: to anhydrous solution of particular amine (ethylenediamine, tris(2-aminoethyl)amine, triethylenetetramine, 4,7,10-trioxa-1,13-tridecanediamine) (0.190 mol) in methanol $(50 \mathrm{~mL})$, cooled in ice-water bath to temperature $0^{\circ} \mathrm{C}$, solution of ester intermediate $(10 \mathrm{~g} ; 0.015 \mathrm{~mol})$ in $30 \mathrm{~mL}$ of methanol was added dropwise within 2 hours, maintaining reduced temperature. Afterwards, solution was allowed to warm to room temperature, and stirred for next 10 days. Then, excess of solvent was evaporated and dendrimers were extracted with cold diethyl ether, obtaining pure products shown in Figure 1. Structures and molar mass of dendrimers were proved by ${ }^{1} \mathrm{H}$ and ${ }^{13} \mathrm{C}$ analysis, and ESI-positive MS analysis, respectively.

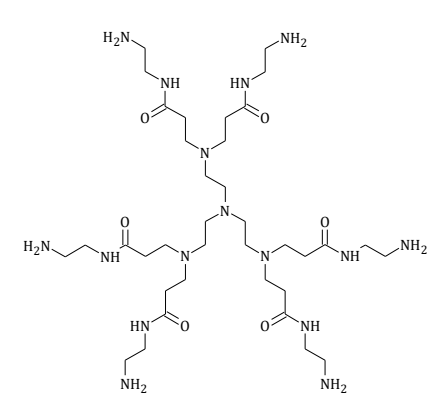

2

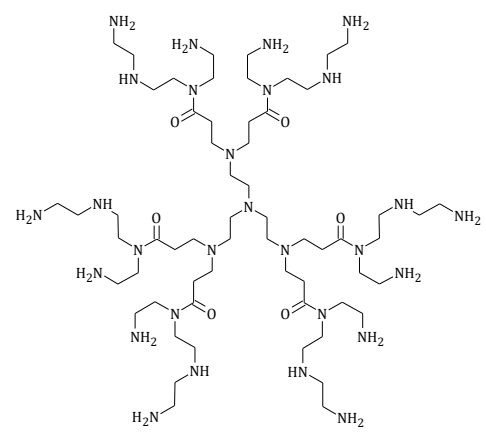

3

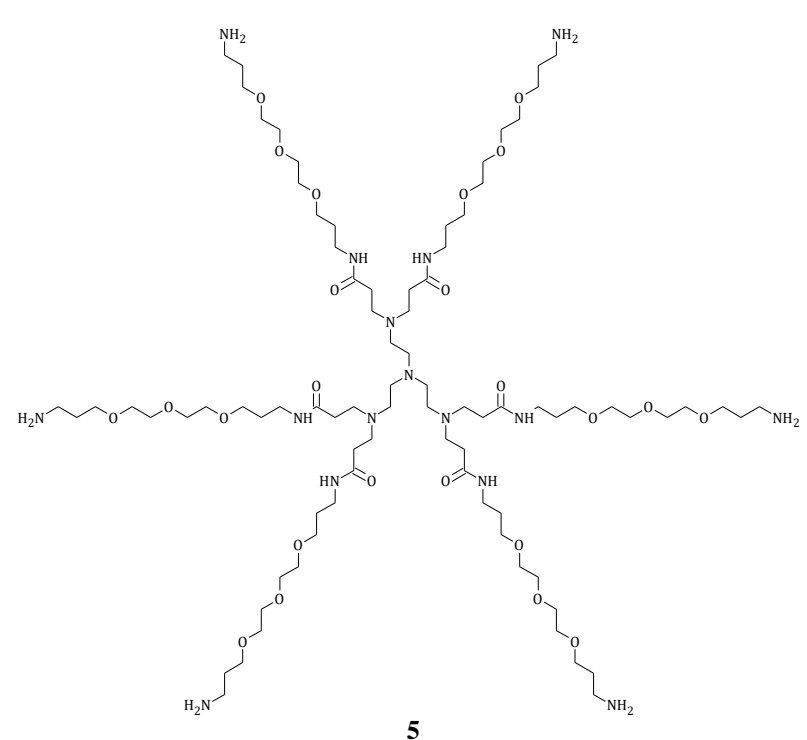

4

Fig. 1: Structural patterns of dendrimers with tris(2-aminoethyl)amine as amine core and various amino-components: ethylenediamine (2), triethylenetetramine (3), tris(2-aminoethyl)amine (4) and 4,7,10-trioxa-1,13-tridecanediamine (5). 


\subsection{Synthesis of hybrid materials}

Syntheses of $\mathrm{SiO}_{2}$-dendrimer materials were performed by the reaction between commercially available silica-gel surface modified with isocyanate groups and obtained dendrimers (section 2.1) (Fig. 2). Generally, anhydrous solution of dendrimer $(5.4 \mathrm{mmol})$ in $30 \mathrm{~mL}$ of methanol was cooled in dry ice-isopropanol bath to the temperature at least $-50^{\circ} \mathrm{C}$. To stirred solution, $6 \mathrm{~g}$ of $\mathrm{SiO}_{2}$ - $\mathrm{NCO}$ (loading $=1.41 \mathrm{mmol} \mathrm{g}^{-1}$ ) were added batchwise, not to let temperature rise above $-50^{\circ} \mathrm{C}$, and then stirred for 3 hours in the atmosphere of nitrogen, maintaining low temperature. Afterwards, cooling bath was removed, mixture was allowed to warm to room temperature and stirred upon overnight. Excess of unreacted dendrimer solution was filtered off, solid was washed with DCM $(3 \times 10 \mathrm{~mL})$ and dried under removed pressure, yielding light yellow powder.

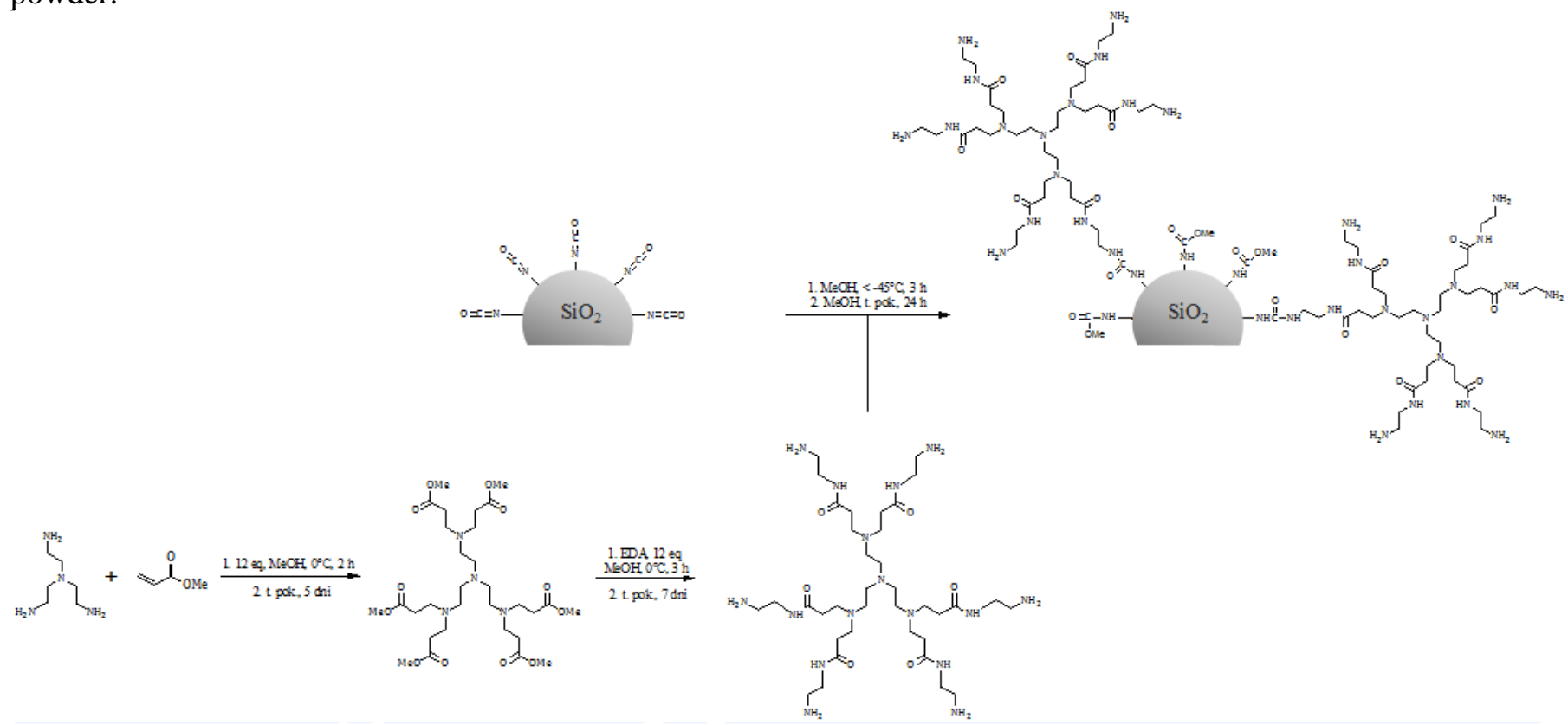

Fig. 2: Reaction scheme of functionalization silica surface with exemplary dendrimer $\mathbf{2}$.

\subsection{Heavy metals ions adsorption experiments}

Adsorption studies were performed using metal perchlorates solutions buffered in sodium acetate/acetic acid buffer: $\mathrm{Cu}\left(\mathrm{ClO}_{4}\right)_{2}, \mathrm{Ni}\left(\mathrm{ClO}_{4}\right)_{2}$ and $\mathrm{Co}\left(\mathrm{ClO}_{4}\right)_{2}$, which concentrations were calculated using spectrophotometric assays with wavelengths determined at $236 \mathrm{~nm}, 393 \mathrm{~nm}$ and $513 \mathrm{~nm}$ for $\mathrm{Cu}(\mathrm{II}), \mathrm{Ni}(\mathrm{II})$ and $\mathrm{Co}(\mathrm{II})$, respectively. Preparation of adsorption isotherms was available by general procedure: $10 \mathrm{~mL}$ of metal perchlorates at six different concentrations $(0.1,0.5,1,2,5,10 \mathrm{mM}$ for $\mathrm{Cu}(\mathrm{II}) ; 1,2,5,10,15,20,30 \mathrm{mM}$ for $\mathrm{Ni}(\mathrm{II})$ and $\mathrm{Co}(\mathrm{II}))$, buffered to $\mathrm{pH} 5.4$ were dosed to $10 \mathrm{mg}$ set of each $\mathrm{SiO}_{2}$-dendrimer hybrid material. After stirring for 24 hours in room temperature, adsorption reactions reached equilibrium state, and final metals concentrations were established using UV-Vis assays. The amount of each metal adsorbed on hybrid materials was quantified with Eq. 1: $\mathrm{q}_{\mathrm{eq}}-$ amount of metal adsorbed $\left[\mathrm{mg} \mathrm{g}^{-1}\right] ; \mathrm{c}_{0}$ and $\mathrm{c}_{\mathrm{eq}}-$ starting and equilibrium concentration of metal ions $[\mathrm{mM}] ; \mathrm{V}$ - volume of added metal ions solution [mL]; $\mathrm{m}$ - mass of hybrid material sample [mg].

For kinetic studies, the general procedure involved adding of $20 \mathrm{~mL}$ of metal perchlorates solution (5 $\mathrm{mM}$ for $\mathrm{Cu}$ (II)

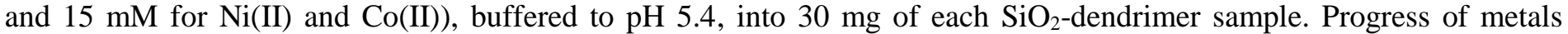
adsorption was monitored by calculation of the amount of metal adsorbed on materials in pre-set time intervals, using Eq (2): $\mathrm{q}_{\mathrm{t}}$ - amount of metal adsorbed at the time $t\left[\mathrm{mg} \mathrm{g}^{-1}\right] ; \mathrm{c}_{0}$ and $\mathrm{c}_{\mathrm{t}}$ - initial concentration of metal ions and at the time $t$, respectively $[\mathrm{mM}] ; \mathrm{V}$ - volume of added metal ions solution $[\mathrm{mL}] ; \mathrm{m}$ - mass of hybrid material sample [mg]. 
Thermodynamic studies were performed as follows: buffered to $\mathrm{pH} 5.4$ solutions of metal perchlorates $(5 \mathrm{~mL})$ at concentration $5 \mathrm{mM}$ for $\mathrm{Cu}$ (II) and $15 \mathrm{mM}$ for $\mathrm{Ni}$ (II) and $\mathrm{Co}$ (II) were added to the set of $10 \mathrm{mg}$ each material's and stirred for 24 hours at temperatures $301 \pm 1 \mathrm{~K}, 313 \pm 1 \mathrm{~K}$ and $328 \pm 1 \mathrm{~K}$. The amount of metals adsorbed on each were established in accordance to Eq. 1.

$$
\begin{aligned}
\mathrm{q}_{\mathrm{eq}} & =\frac{\left(\mathrm{c}_{0}-\mathrm{c}_{\mathrm{eq}}\right) \cdot \mathrm{V}}{\mathrm{m}} \\
\mathrm{q}_{\mathrm{t}} & =\frac{\left(\mathrm{c}_{0}-\mathrm{c}_{\mathrm{t}}\right) \cdot \mathrm{V}}{\mathrm{m}}
\end{aligned}
$$

\section{Results and discussion}

\subsection{Synthesis of hybrid materials $\mathrm{SiO}_{2}$-dendrimer}

The main subject of conducted studies was to synthesize a group of silica-based hybrid materials grafted with dendrimers' nanoparticles, as novel adsorbents toward various heavy metals ions. The first step of synthesis involved preparing of poly(amidoamine) dendrimers with tris(2-aminoethyl)amine as amine core and various amino-terminal components. Synthesis was based on: (1) branching, as the reaction between amine core and methyl acrylate, leading to ester-precursor of dendrimers; (2) amidation of ester-intermediate, using four structurally diverse amino components. Both, dendrimers and ester-intermediate were analyzed with ESI-positive MS analysis, and final dendrimers structures were proved with ${ }^{1} \mathrm{H}$ and ${ }^{13} \mathrm{C}$ NMR analysis. It is noteworthy that MS spectra of dendrimers shown molecular peaks $[\mathrm{PAMAM}+\mathrm{H}]^{+}$with relatively low intensity, while fragmentation peaks referring to various fragmentation ions ([PAMAM $-x$ amine $+n \mathrm{H}]^{\mathrm{n}+}$ and [PAMAM $-x \mathrm{CH}_{2} \mathrm{CH}_{2} \mathrm{C}(\mathrm{O})$-amine $\left.+n \mathrm{H}\right]^{\mathrm{n}+}, x=1 ; 2 ; 3$ ) were observed with higher abundance, what has already been reported in the literature [11]. Another phenomenon was observed for ${ }^{1} \mathrm{H}-\mathrm{NMR}$ spectra of prepared dendrimers, which did not exhibit appearance of amide protons, according to the utilization of deuterated methanol as probes solvent [12].

Synthesized dendrimers were further utilized as grafting nanoagents for silica particles. Reactions between commercially available silica-gel functionalized with surface isocyanate group and each dendrimer were held in anhydrous methanol. First stage of reactions was conducted for 3 hours at temperature at most $-50^{\circ} \mathrm{C}$, in order to avoid reaction between isocyanate groups and solvent molecules. Afterwards, mixtures temperature was allowed to rise to $25^{\circ} \mathrm{C}$, providing suppression of unreacted -NCO groups with methanol. Successful surface-graftings were proved with IR analysis (Fig. 3), observing bands corresponding to $\mathrm{C}=\mathrm{O}_{\text {amide }}, \mathrm{N}-\mathrm{H}_{\text {amide }}$ and $-\mathrm{CH}_{2}$ - vibrations, at 1637,1570 and $2942 \mathrm{~cm}^{-1}$, respectively. Each spectrum also shows a broad peak with maximum at approximately $3477 \mathrm{~cm}^{-1}$, which corresponds to silanol groups remained on silica surface and may overlap peak referring to terminal amine $-\mathrm{NH}_{2}$ groups. Moreover, loading of dendritic structures on obtained materials was determined using simple alkacymetric titrations (Table 1), resulting in loading values between $0.078 \mathrm{mmol} \mathrm{g}^{-1}$ and $0.310 \mathrm{mmol} \mathrm{g}^{-1}$. The highest loading value was established for $\mathrm{SiO}_{2}-(\mathbf{2})$ material, in agreement with the most compact structure of dendrimer $\mathbf{2}$ structure, while the lowest value was reached for material $\mathrm{SiO}_{2}-(\mathbf{5})$ grafted with the most structurally expanded dendrimer $\mathbf{5}$.

Preparation of above-described hybrid materials was strongly associated with the idea of designing of novel, highly efficient and eco-friendly adsorbents, containing nano-scaled chelating agent covalently bound to particular platform. Following studies are based on utilization of silica, as inorganic platform of designed hybrid materials, which exhibit very poor adsorptive properties, when unmodified [13]. Also, the influence of utilized amino-components on adsorptive properties of hybrid materials was established. Additionally, future plans for adsorption studies contain determination of reusability of obtained adsorbents towards heavy metal ions adsorption using either acidic environment $(\mathrm{HCl}, \mathrm{pH}<2)$ or counter-chelating agent, such as ethylenediaminetetraacetic acid (EDTA). Reusability will be determined as the number of sorption/desorption cycles needed for reaching maximal adsorption capacity value higher than $90 \%$ of primal value. 


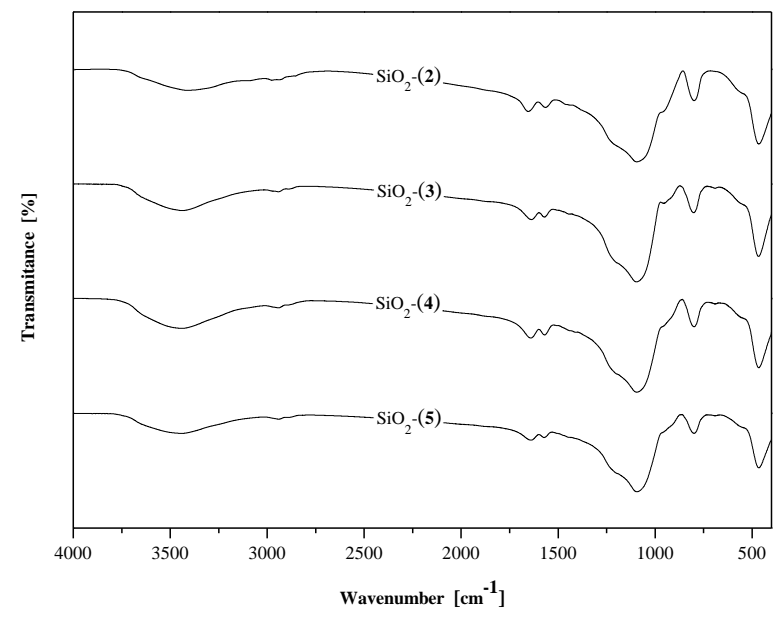

Table 1: The amount of dendrimers grafted onto silica surface (loading).

\begin{tabular}{|c|c|}
\hline Hybrid material & $\begin{array}{c}\text { Loading } \\
{\left[\mathrm{mmol} \mathrm{g}^{-1}\right]}\end{array}$ \\
\hline $\mathrm{SiO}_{2}-(\mathbf{2})$ & 0.310 \\
\hline $\mathrm{SiO}_{2}-(\mathbf{3})$ & 0.152 \\
\hline $\left.\mathrm{SiO}_{2}-\mathbf{4}\right)$ & 0.155 \\
\hline $\left.\mathrm{SiO}_{2}-\mathbf{5}\right)$ & 0.078 \\
\hline
\end{tabular}

Fig. 3: IR spectra of $\mathrm{SiO} 2$-dendrimer hybrid materials.

\subsection{Heavy metals ions adsorption on $\mathrm{SiO}_{2}$-dendrimer hybrid materials}

Synthesized materials were investigated for their adsorptive properties toward predominantly occurred heavy metal ions: copper(II), cobalt (II) and nickel (II) ions. Adsorption experiments involved preparing of adsorption isotherms, and also kinetic and thermodynamic studies, in order to fully describe adsorptive nature of $\mathrm{SiO}_{2}$-dendrimer hybrid materials. All values describing adsorptive properties of synthesized materials were calculated on the basis of linear regressions' coefficients (slopes and intercepts) defined with $\mathrm{R}^{2}$ correlation coefficients. Moreover, standard deviations of calculated values were computationally obtained using total derivative method.

\subsubsection{Adsorption isotherms}

Investigation of adsorption isotherms leads to important parameters of particular material, in a reference mainly to maximal adsorption capacity and mechanism of analyte uptake. There are several isothermal models, however the most frequently used are Langmuir and Freundlich, which postulate forming of adsorbate monolayer (assuming equality of all binding sites, and excluding intermolecular effects of adsorbate) and multilayer (caused by heterogeneity of material's surface), respectively [14]. In order to determine isothermal model of heavy metals adsorption processes on synthesized materials, experimental data were fitted to linear forms of Langmuir (Eq. 3) and Freundlich (Eq. 4) adsorption isotherms, where: $\mathrm{q}_{\mathrm{m}}$ - maximal amount of metal adsorbed $\left[\mathrm{mg} \mathrm{g}^{-1}\right] ; \mathrm{K}_{\mathrm{L}}-$ Langmuir constant $\left[\mathrm{dm}^{3} \mathrm{mg}^{-1}\right] ; \mathrm{K}_{\mathrm{F}}-$ Freundlich constant $\left[\mathrm{mg} \mathrm{g}^{-1}\left(\mathrm{~L} \mathrm{mg}^{-1}\right)^{1 / n}\right] ; 1 / n$ - empirical coefficient, describing adsorption intensity and heterogeneity of adsorbent.

$$
\begin{gathered}
\frac{c_{\text {eq }}}{q_{\text {eq }}}=\frac{c_{\text {eq }}}{q_{m}}+\frac{1}{q_{m} K_{L}} \\
\log q_{\text {eq }}=\log K_{F}+\frac{1}{n} \log c_{e q}
\end{gathered}
$$

Obtained experimental data were fitted to both, Langmuir and Freundlich adsorption isotherm models. The great majority of adsorption processes followed Langmuir isotherm model, what was proved by $\mathrm{R}^{2}$-values $\left(\mathrm{R}^{2}>0.9875\right)$, much higher than those for Freundlich isotherm model, indicating that rate-limiting step of adsorption was connected with exhaustion of binding sites in each hybrid material. However, it is noteworthy that for material grafted with dendrimer $\mathbf{4}$ and 5, adsorption of copper(II) ions followed partially Langmuir and Freundlich model, what was an effect of dendrimers' size making adsorbate less attachable. Moreover, on the basis of Langmuir isotherm, maximal adsorption capacities of all materials toward each metal were calculated. In general, material grafted with dendrimer 2, having the smallest and 
most compact ultimate amino-component (ethylenediamine) exhibited high adsorption capacity for all metals, ranging between 93.6 and $104.6 \mathrm{mg} \mathrm{g}^{-1}$, while material functionalized with dendrimer containing triethylenetetramine domain exhibited the lowest average binding capacity $\left(32.8-86.7 \mathrm{mg} \mathrm{g}^{-1}\right)$, what was connected with its long straight-chain On the other hand, dendrimer $\mathbf{5}$, as well built of long straight-chain 4,7,10-trioxa-1,13-tridecanediamine, exhibited the maximal adsorption capacity toward nickel(II) and cobalt(II) ions, 116.6 and $101.1 \mathrm{mg} \mathrm{g}^{-1}$, respectively, what was influenced by the appearance of oxygen atoms, enhancing binding affinity towards particular ions. Furthermore, the highest efficiency of metal ions removal was observed for their most diluted solutions, what was proved with a decrease of distribution coefficient value $\left(\mathrm{K}_{\mathrm{d}}\right)$ (chapter 3.2.3) with an increment of ions concentration, reaching values greater than 1 for the lowest analytes' concentrations, indicating on high affinity towards solid phase (adsorbent). The lowest $\mathrm{K}_{\mathrm{d}}$ values were obtained for $\mathrm{SiO}_{2}-(2)$ and $\mathrm{SiO}_{2}-(3)$ materials, indicating on the lowest adsorption efficiency, earlier proved with maximal adsorption capacity values.

Table 2: Isothermal parameters for heavy metal ions adsorption on $\mathrm{SiO}_{2}$-dendrimer materials.

\begin{tabular}{|c|c|c|c|c|c|c|c|}
\hline \multirow[b]{2}{*}{ Metal ion } & \multirow[b]{2}{*}{ Hybrid material } & \multicolumn{3}{|c|}{ Langmuir isotherm } & \multicolumn{3}{|l|}{ Freundlich isotherm } \\
\hline & & $\begin{array}{c}\mathrm{K}_{\mathrm{L}} \\
{\left[\mathrm{L} \mathrm{mg}^{-1}\right]}\end{array}$ & $\begin{array}{c}\mathrm{qm}_{\mathrm{m}} \\
{\left[\mathrm{mg} \mathrm{g}^{-1}\right]}\end{array}$ & $\mathrm{R}^{2}$ & $\begin{array}{c}\mathrm{K}_{\mathrm{F}} \\
{\left[\mathrm{mg} \mathrm{g}^{-1}\left(\mathrm{~L} \mathrm{mg}^{-1}\right)^{1 / \mathrm{n}}\right]}\end{array}$ & $1 / \mathrm{n}$ & $\mathrm{R}^{2}$ \\
\hline \multirow{4}{*}{$\mathrm{Cu}(\mathrm{II})$} & $\mathrm{SiO}_{2}-(2)$ & $0.020 \pm 0.006$ & $104.6 \pm 5.6$ & 0.9888 & $6.81 \pm 1.02$ & $0.45 \pm 0.04$ & 0.9754 \\
\hline & $\mathrm{SiO}_{2}-(3)$ & $0.007 \pm 0.001$ & $70.6 \pm 3.4$ & 0.9908 & $1.24 \pm 0.26$ & $0.64 \pm 0.05$ & 0.9847 \\
\hline & $\mathrm{SiO}_{2}-(4)$ & $0.013 \pm 0.005$ & $62.9 \pm 5.5$ & 0.9707 & $4.12 \pm 0.47$ & $0.42 \pm 0.03$ & 0.9788 \\
\hline & $\mathrm{SiO}_{2}-(\mathbf{5})$ & $0.006 \pm 0.002$ & $19.8 \pm 2.2$ & 0.9504 & $0.59 \pm 0.03$ & $0.59 \pm 0.03$ & 0.9882 \\
\hline \multirow{4}{*}{$\mathrm{Ni}(\mathrm{II})$} & $\mathrm{SiO}_{2}-(2)$ & $0.012 \pm 0.004$ & $93.6 \pm 2.8$ & 0.9956 & $12.95 \pm 2.33$ & $0.28 \pm 0.03$ & 0.9436 \\
\hline & $\mathrm{SiO}_{2}-(\mathbf{3})$ & $0.006 \pm 0.001$ & $86.7 \pm 3.1$ & 0.9936 & $6.55 \pm 0.90$ & $0.35 \pm 0.02$ & 0.9792 \\
\hline & $\mathrm{SiO}_{2}-(4)$ & $0.004 \pm 0.001$ & $111.7 \pm 3.6$ & 0.9949 & $2.58 \pm 0.98$ & $0.52 \pm 0.06$ & 0.9298 \\
\hline & $\mathrm{SiO}_{2}-(\mathbf{5})$ & $0.025 \pm 0.015$ & $116.6 \pm 3.2$ & 0.9962 & $46.49 \pm 4.13$ & $0.12 \pm 0.02$ & 0.9275 \\
\hline \multirow{4}{*}{$\mathrm{Co}(\mathrm{II})$} & $\mathrm{SiO}_{2}-(2)$ & $0.023 \pm 0.010$ & $99.1 \pm 2.0$ & 0.9979 & $26.33 \pm 3.92$ & $0.19 \pm 0.02$ & 0.9169 \\
\hline & $\mathrm{SiO}_{2}-(3)$ & $0.012 \pm 0.005$ & $32.8 \pm 1.2$ & 0.9934 & $4.40 \pm 1.82$ & $0.28 \pm 0.07$ & 0.7748 \\
\hline & $\mathrm{SiO}_{2}-(4)$ & $0.016 \pm 0.012$ & $60.8 \pm 3.1$ & 0.9875 & $20.48 \pm 3.68$ & $0.15 \pm 0.03$ & 0.9272 \\
\hline & $\mathrm{SiO}_{2}-(\mathbf{5})$ & $0.014 \pm 0.006$ & $101.1 \pm 3.0$ & 0.9955 & $15.84 \pm 3.88$ & $0.26 \pm 0.04$ & 0.8885 \\
\hline
\end{tabular}

\subsubsection{Adsorption kinetics}

Performing kinetic studies demands utilization of high excess of metal ion solutions, to fully suppress binding sites of adsorbents. Determination of amount metal adsorbed in time intervals contributes to assessment of particular adsorption's kinetic model. Most widely used adsorption kinetic models are pseudo-first-order and pseudo-second-order kinetics, which state that rate-limiting step of adsorption is connected with material's adsorption capacity or mechanism of adsorbent-analyte interactions, respectively. Pseudo-first-order kinetics follows linear form presented in Eq. 5, while linear plot of pseudo-second-order kinetic model is represented by Eq. 6 [15].

$$
\begin{gathered}
\log \left(\mathrm{q}_{\mathrm{e}}-\mathrm{q}_{\mathrm{t}}\right)=\log \mathrm{q}_{\mathrm{e}}-\frac{\mathrm{k}_{1}}{2.303} \mathrm{t} \\
\frac{\mathrm{t}}{\mathrm{q}_{\mathrm{t}}}=\frac{1}{\mathrm{k}_{2} \mathrm{q}_{\mathrm{e}}^{2}}+\frac{1}{\mathrm{q}_{\mathrm{e}}} \mathrm{t}
\end{gathered}
$$

In order to determine which kinetic model adsorption reactions follow, $\mathrm{R}^{2}$-values collected in Table 3 for pseudofirst- and pseudo-second-order kinetics were compared. Good complementarity of kinetic and isothermal models indicates that majority of heavy metal adsorption processes on hybrid materials follow pseudo-second-order kinetics. 
Table 3: Kinetic parameters for heavy metal ions adsorption on $\mathrm{SiO}_{2}$-dendrimer materials.

\begin{tabular}{|c|c|c|c|c|c|}
\hline \multirow[b]{2}{*}{ Metal ion } & \multirow[b]{2}{*}{ Hybrid material } & \multicolumn{2}{|c|}{ Pseudo-first-order } & \multicolumn{2}{|c|}{ Pseudo-second-order } \\
\hline & & $\begin{array}{c}\mathrm{k}_{1} \\
{\left[\mathrm{~h}^{-1}\right]}\end{array}$ & $\mathrm{R}^{2}$ & $\begin{array}{c}\mathrm{k}_{2} \\
{\left[\mathrm{~g} \mathrm{mg}^{-1} \mathrm{~h}^{-1}\right]}\end{array}$ & $\mathrm{R}^{2}$ \\
\hline \multirow{4}{*}{$\mathrm{Cu}(\mathrm{II})$} & $\mathrm{SiO}_{2}-(\mathbf{2})$ & $0.078 \pm 0.001$ & 0.9964 & $0.0013 \pm 0.0001$ & 0.7841 \\
\hline & $\mathrm{SiO}_{2}-(\mathbf{3})$ & $0.008 \pm 0.002$ & 0.5293 & $0.0939 \pm 0.0132$ & 0.9963 \\
\hline & $\mathrm{SiO}_{2}-(\mathbf{4})$ & $0.182 \pm 0.006$ & 0.9859 & $0.0073 \pm 0.0003$ & 0.9976 \\
\hline & $\mathrm{SiO}_{2}-(\mathbf{5})$ & $0.136 \pm 0.003$ & 0.9918 & $0.0031 \pm 0.0008$ & 0.4211 \\
\hline \multirow{4}{*}{$\mathrm{Ni}(\mathrm{II})$} & $\mathrm{SiO}_{2}-(2)$ & $0.035 \pm 0.005$ & 0.7630 & $0.0040 \pm 0.0003$ & 0.9922 \\
\hline & $\mathrm{SiO}_{2}-(\mathbf{3})$ & $0.025 \pm 0.005$ & 0.6261 & $0.0119 \pm 0.0008$ & 0.9966 \\
\hline & $\mathrm{SiO}_{2}-(\mathbf{4})$ & $0.099 \pm 0.007$ & 0.9384 & $0.0034 \pm 0.0002$ & 0.9958 \\
\hline & $\mathrm{SiO}_{2}-(\mathbf{5})$ & $0.036 \pm 0.005$ & 0.7881 & $0.0034 \pm 0.0002$ & 0.9948 \\
\hline \multirow{4}{*}{$\mathrm{Co}(\mathrm{II})$} & $\mathrm{SiO}_{2-}-(\mathbf{2})$ & $0.061 \pm 0.004$ & 0.9417 & $0.0024 \pm 0.0002$ & 0.9834 \\
\hline & $\mathrm{SiO}_{2}-(\mathbf{3})$ & $0.715 \pm 0.007$ & 0.8950 & $0.0119 \pm 0.0009$ & 0.9919 \\
\hline & $\mathrm{SiO}_{2}-(\mathbf{4})$ & $0.205 \pm 0.004$ & 0.9937 & $0.0052 \pm 0.0004$ & 0.9915 \\
\hline & $\mathrm{SiO}_{2-(5)}$ & $0.052 \pm 0.004$ & 0.9158 & $0.0024 \pm 0.0002$ & 0.9727 \\
\hline
\end{tabular}

\subsubsection{Adsorption thermodynamics}

On the basis of simultaneous adsorption experiments conducted in various temperatures, thermodynamic parameters, such as standard enthalpy $\left(\Delta \mathrm{H}^{\circ}\right)$, entropy $\left(\Delta \mathrm{S}^{\circ}\right)$ and Gibbs free energy changes $\left(\Delta \mathrm{G}^{\circ}\right)$ might be calculated, which strictly indicate on the nature of adsorption process. Both, $\Delta \mathrm{H}^{\circ}$ and $\Delta \mathrm{S}^{\circ}$ values are obtained from linear plot, described by Eq. 7 , where: $\mathrm{R}$ - universal gas constant $\left(8.314 \mathrm{~J} \mathrm{~mol}^{-1} \mathrm{~K}^{-1}\right) ; \mathrm{K}_{\mathrm{d}}$ - distribution coefficient, obtainable as $\mathrm{c}_{\mathrm{Ae}} / \mathrm{c}_{\mathrm{e}}$ ratio $\left(\mathrm{c}_{\mathrm{Ae}}\right.$ and $\mathrm{c}_{\mathrm{e}}$ are equilibrium metal concentration adsorbed on material $\left[\mathrm{mg} \mathrm{g}^{-1}\right]$ and remained in solution $\left[\mathrm{mg} \mathrm{L}^{-1}\right]$, respectively). Moreover, $\Delta \mathrm{G}^{\circ}$ values for experiments maintained in each temperature might be calculated on the basis of Eq. 8 .

$$
\begin{aligned}
& \ln \mathrm{K}_{\mathrm{d}}=\frac{\Delta \mathrm{S}^{\circ}}{\mathrm{R}}-\frac{\Delta \mathrm{H}^{\circ}}{\mathrm{RT}} \\
& \Delta \mathrm{G}^{\circ}=-\mathrm{RT} \ln \mathrm{K}_{\mathrm{d}}
\end{aligned}
$$

All calculated data for adsorption processes shown only positive values of standard enthalpies, indicating on endothermic nature of described processes. It must be highlighted that values obtained for experiments involving nickel(II) and cobalt(II) ions were relatively similar for particular material, whereas values for copper(II) ions varied significantly. Furthermore, data presents only negative values for Gibbs free energy changes, what jointly with enthalpies values indicates on spontaneous, endothermic character of heavy metals ions adsorption on $\mathrm{SiO}_{2}$-dendruimer hybrid materials.

\begin{tabular}{|c|c|c|c|c|c|c|c|}
\hline \multirow{2}{*}{ Metal ion } & \multirow{2}{*}{ Hybrid material } & \multirow{2}{*}{$\begin{array}{c}\Delta \mathrm{H}^{\circ} \\
{\left[\mathrm{kJ} \mathrm{mol}^{-1}\right]}\end{array}$} & \multirow{2}{*}{$\begin{array}{c}\Delta \mathrm{S}^{\circ} \\
{\left[\mathrm{J} \mathrm{mol}^{-1} \mathrm{~K}^{-1}\right]}\end{array}$} & \multirow{2}{*}{$\mathrm{R}^{2}$} & \multicolumn{3}{|c|}{$\Delta \mathrm{G}^{\circ}\left[\mathrm{kJ} \mathrm{mol}^{-1}\right]$} \\
\hline & & & & & $301 \mathrm{~K}$ & $313 \mathrm{~K}$ & $328 \mathrm{~K}$ \\
\hline \multirow{4}{*}{$\mathrm{Cu}(\mathrm{II})$} & $\mathrm{SiO}_{2}-(\mathbf{2})$ & $40.4 \pm 0.8$ & $160.7 \pm 2.4$ & 0.9997 & -7.976 & -9.959 & -12.315 \\
\hline & $\mathrm{SiO}_{2}-(3)$ & $69.5 \pm 10.1$ & $236.9 \pm 32.1$ & 0.9794 & -6.900 & -8.423 & -9.527 \\
\hline & $\mathrm{SiO}_{2}-(4)$ & $22.2 \pm 4.8$ & $91.2 \pm 15.3$ & 0.9555 & -4.907 & -7.760 & -10.020 \\
\hline & $\mathrm{SiO}_{2}-(5)$ & $51.8 \pm 7.8$ & $189.0 \pm 25.0$ & 0.9777 & -1.570 & -5.166 & -7.979 \\
\hline \multirow{4}{*}{$\mathrm{Ni}(\mathrm{II})$} & $\mathrm{SiO}_{2}-(2)$ & $14.6 \pm 0.8$ & $55.9 \pm 2.7$ & 0.9967 & -2.306 & -2.821 & -3.715 \\
\hline & $\mathrm{SiO}_{2}-(\mathbf{3})$ & $14.6 \pm 0.6$ & $49.6 \pm 1.9$ & 0.9983 & -0.424 & -0.966 & -1.670 \\
\hline & $\mathrm{SiO}_{2}-(4)$ & $12.1 \pm 0.9$ & $43.1 \pm 2.7$ & 0.9949 & -0.989 & -1.365 & -2.068 \\
\hline & $\mathrm{SiO}_{2}-(\mathbf{5})$ & $23.5 \pm 1.9$ & $84.3 \pm 6.1$ & 0.9934 & -2.007 & -2.999 & -4.139 \\
\hline \multirow{4}{*}{$\mathrm{Co}(\mathrm{II})$} & $\mathrm{SiO}_{2}-(\mathbf{2})$ & $11.2 \pm 0.7$ & $49.5 \pm 2.2$ & 0.9961 & -3.733 & -4.302 & -4.998 \\
\hline & $\mathrm{SiO}_{2}-(\mathbf{3})$ & $7.2 \pm 0.3$ & $31.1 \pm 1.1$ & 0.9978 & -2.237 & -2.539 & -3.027 \\
\hline & $\mathrm{SiO}_{2}-(\mathbf{4})$ & $10.3 \pm 0.8$ & $45.7 \pm 2.5$ & 0.9942 & -3.517 & -3.942 & -4.679 \\
\hline & $\mathrm{SiO}_{2}-(\mathbf{5})$ & $21.9 \pm 1.8$ & $80.2 \pm 5.7$ & 0.9934 & -2.447 & -3.139 & -4.459 \\
\hline
\end{tabular}

Table 4: Thermodynamic parameters for heavy metal ions adsorption on $\mathrm{SiO}_{2}$-dendrimer materials. 


\section{Conclusion}

The group of novel $\mathrm{SiO}_{2}$-dendrimer hybrid materials using various poly(amidoamine) dendrimers as grafting nanoagents was synthesized and studied for their adsorptive properties toward heavy metals ions. Successful synthesis and characterization of materials and their building blocks were conducted using spectrometric and spectroscopic assays. Hybrid materials were submitted to examination of their chelating properties towards heavy metals ions, involving isothermal, kinetic and thermodynamic studies, using spectrophotometric assays. All coefficients describing adsorptive nature of materials were calculated on the basis of linear regressions' slopes and intercepts values, encumbered with standard deviations obtained from total derivative computational method. All materials shown irregular, but relatively high binding affinity, reaching values even higher than $100 \mathrm{mg} \mathrm{g}^{-1}$ for materials with grafting loading between $0.078-0.310 \mathrm{mmol} \mathrm{g}^{-1}$. Differences in obtained adsorptive coefficients values prove significant influence of ultimate amino-component on overall material's binding capability. Furthermore, successful synthesis and adsorption analysis of synthesized hybrid materials leads to the novel tool for pre-concentration or removal of particular analytes in radically diluted solutions. All adsorbents will also be studied for their reusability, using different desorbing agents (HCl and EDTA). To summarize, both silica and dendrimers are biocompatible materials, exhibiting low toxicity, thus obtained materials might open the new way of research in the field of novel platforms for direct bioactive molecules' transport.

\section{Acknowledgements}

This work was supported by Project no. POWR.03.02.00-00-1026/16.

\section{References}

[1] Reza R., "Heavy metal contamination and its indexing approach for river water," Int. J. Environ. Sci. Tech. vol. 7, pp. 785-792, 2010.

[2] Rajaganapathy V., Xavier F., Sreekumar D., Mandal P.K., "Heavy Metal Contamination in Soil, Water and Fooder and their Presence in Livestock and Products: A Review," J. Environ. Sci. Technol., vol. 4, pp. 234-249, 2011.

[3] Hasan Z., Jhung S. H., "Removal of hazardous organics from water using metal-organic frameworks (MOFs): Plausible mechanisms for selective adsorptions," J. Haz. Mater., vol. 283, pp. 329-339, 2015.

[4] Mohan D., Sarswat A., Ok Y. S., Pittman C. U. Jr., "Organic and inorganic contaminants removal from water with biochar, a renewable, low cost and sustainable adsorbent - A critical review," Biores. Technol., vol. 160, pp. 191-202, 2014.

[5] Behrens S., "Preparation of functional magnetic nanocomposites and hybrid materials: recent progress and future directions," Nanoscale, vol. 3, pp. 877-892, 2011.

[6] Ruiz-Hitzky E., Aranda P., Darder M., Rytwo G., "Hybrid materials based on clays for environmental and biomedical applications," J. Mater. Chem., vol. 20, pp. 9306-9321, 2010.

[7] Larraza I., Lopez-Gonzalez M., Corrales T., Marcelo G., "Hybrid materials: Magnetite-PolyethylenimineMontmorillonite, as magnetic adsorbents for Cr(VI) water treatment," Journal of Colloid and Interface Science, vol. 385, pp. 24-33, 2012.

[8] Hoffmann F., Froba M., "Vitalising porous inorganic silica networks with organic functions_PMOs and related hybrid materials" Chem. Soc. Rev., vol. 40, pp. 608-620, 2011.

[9] Pawlaczyk M., Kurczewska J., Schroeder G., "Nanomaterials Modification by Dendrimers - A Review," World J. Res. Rev., vol. 6, pp. 14-30, 2018.

[10] Diallo M. S., Christie S., Swaminathan P., Johnson J. H., Goddard W. A., "Recovery of Cu(II) from aqueous solutions using PAMAM dendrimers with ethylene diamine core," Environ. Sci. Technol., vol. 39, pp. 1366-1377, 2005.

[11] Kurczewska J., Cegłowski M., Messyasz B., Schroeder G., "Dendrimer-functionalized halloysite nanotubes for effective drug delivery," Appl. Clay Sci., vol. 153, pp. 134-143, 2018.

[12] Oddone N., Zambrana A. I., Tassano M., Porcal W., Cabral P., Benech J. C., "Cell uptake mechanisms of PAMAM G4-FITC dendrimer in human myometrial cells," J. Nanopart. Res., vol. 15, pp. 1776-1789, 2013. 
[13] Chiron N., Guilet R., Deydier E., "Adsoeption of $\mathrm{Cu}(\mathrm{II})$ and $\mathrm{Pb}(\mathrm{II})$ onto a grafted silica: isotherms and kinetic models," Water Res., vol. 37, pp. 3079-3086, 2003.

[14] Kara A., Demirbel E., "Kinetic, Isotherm and Thermodynamic Analysis on Adsorption of Cr(VI) Ions from Aqueous Solutions by Synthesis and Characterization of Magnetic-Poly(divinylbenzene-vinylimidazole) Microbeads," Water Air Soil Pollut., vol. 223, pp. 2387-2403, 2012.

[15] Qiu H. Lv L., Pan B., Zhang Q, "Critical review in adsorption kinetic models," J. Zhejiang Univ. Sci. A, vol. 10, pp. 716-724, 2009. 